\title{
Interactive comment on "Biomass burning aerosols in the southern hemispheric midlatitudes as observed with a multiwavelength polarization Raman lidar” by Athena Augusta Floutsi et al.
}

Athena Augusta Floutsi et al.

floutsi@tropos.de

Received and published: 12 July 2020

The authors would like to thank the reviewer for carefully reading the manuscript and providing us with valuable feedback.

With this response, we intent to provide some information regarding some points that the reviewer made.

First of all, we agree that the title chosen for the manuscript was unintentionally misleading. Thanks for pointing that out. The title will be changed accordingly, in order to better reflect the contents of the manuscript, which focuses on the ground-based lidar 
observations made during a long-term (1.5 years) field campaign in Punta Arenas. A possible new title could be "Advection of biomass burning aerosols towards the southern hemispheric mid-latitude station of Punta Arenas as observed with multiwavelength polarization Raman lidar".

Since we do not intent to cover the southern hemispheric midlatitudes as a whole, we will not include any complementary satellite observations which would be far beyond the scope of this paper. In this paper, we want to address the smoke advection towards the usually pristine environment of Punta Arenas.

A more detailed response to the points raised will follow on a later stage.

Interactive comment on Atmos. Chem. Phys. Discuss., https://doi.org/10.5194/acp-2020-453, 2020. 